Pikas E., Koskela L., and Seppänen O. (2017). "Design Management in a Design Office: Solving the Problem of Relevance" In: LC3 2017 Volume II - Proceedings of the 25th Annual Conference of the International Group for Lean Construction (IGLC), Walsh, K., Sacks, R., Brilakis, I. (eds.), Heraklion, Greece, pp. 547-554. DOI: https://doi.org/10.24928/2017/0315

\title{
DESIGN MANAGEMENT IN A DESIGN OFFICE: SOLVING THE PROBLEM OF RELEVANCE
}

\author{
Ergo Pikas ${ }^{1}$, Lauri Koskela ${ }^{2}$, Olli Seppänen ${ }^{3}$
}

\begin{abstract}
In this study we contend that the conceptual foundations of conventional construction design and design management are obsolete, and these need to be substituted by a more comprehensive theoretical basis. As the first paper in the series of three, the main objective of this study is to justify the research by determining the significant problems and challenges related to the design management in a case study organization. Design science research methodology is chosen to develop a scientifically grounded solution with practical relevance. Based on surveys, interviews, database analysis and observations, we conclude that there are significant problems with the design management practice. The major issue with design management is related to the poor and simplistic conceptualization of the design task. The problems summarized in this study facilitate the quest for the proper theoretical understanding and developing a knowledge base for designing a new process model.
\end{abstract}

Keywords: Design, design management, design science research, design management problems

\section{INTRODUCTION}

In this work, we contend that the conceptual foundations of conventional construction design and design management are obsolete (Ballard and Koskela 1998), and these need to be substituted by a more comprehensive theoretical basis. The narrow view of design management is founded on the conceptualization of design production as a transformation of inputs to outputs (Koskela 2000). Design managers focus on managing projects, tasks, resources and contracts (Howell et al. 2010) and less on managing people, processes, environment and technology. This has led to bad consequences (Arnell et al. 1996, Ballard and Koskela 1998, Fosse and Ballard 2016, Koskela et al. 2002, Pikas et al. 2015a, Freire and Alarcón 2002), including but not limited to: Disjointed management, operations and contracting methods; management by deliverables, focused on producing models and drawings, while needs, requirements and alternatives are poorly specified and studied; process and product uncertainty by designers/engineers on what, when and by whom must be designed; misalignment between different design flows etc.

As the first paper in the series of three, within this study the aim is to solve the problem of relevance or in another words, to justify the research purpose. For that, the current state of the practice of design and design management in an Estonian case study design office is analyzed. In following the research method is explained, results of the study are outlined, and conclusions are drawn on significant problems and challenges.

$1 \quad$ Aalto University, Department of Civil Engineering, ergo.pikas@aalto.fi and Tallinn University of Technology, Faculty of Engineering, ergo.pikas@ttu.ee

2 University of Huddersfield, School of Art, Design and Architecture

3 Aalto University, Department of Civil Engineering 


\section{METHOD}

Within the domain of productive sciences, using methodologies addressing how things are is not fit to answer the questions of how things ought to be (Koskela 2008). Thus, in this work a constructivist research approach is used, namely design science research - learning through making (Kuechler and Vaishnavi 2011). The goal is to develop scientifically grounded solutions that are able to solve problems with practical relevance (Rocha et al. 2012).

For the methodological framework, we have adapted the DSR model (see Figure 1) from Hevner (2007), which is the embodiment of three closely related cycles of activities: relevance cycle between environment and design task (understanding context and requirements, and testing of developed constructs); design cycle within DSR domain (building design artefacts/processes and evaluation); rigor cycle between design science research and knowledge base (grounding in theories and methods, domain experience and expertise but also developing new knowledge generated by the research).

As part of this first article (environment in Figure 1) the current situation or "as-is" was analyzed. This stage was divided into three steps and in each of these several methods were used to study the current state of the design and management practices: 1) surveys and interviews for understanding designers and engineers' views on main challenges; 2) database analysis based on the data from enterprise resource planning (ERP) system; 3) observation of one design project for gaining contextual understanding of the problems and challenges.

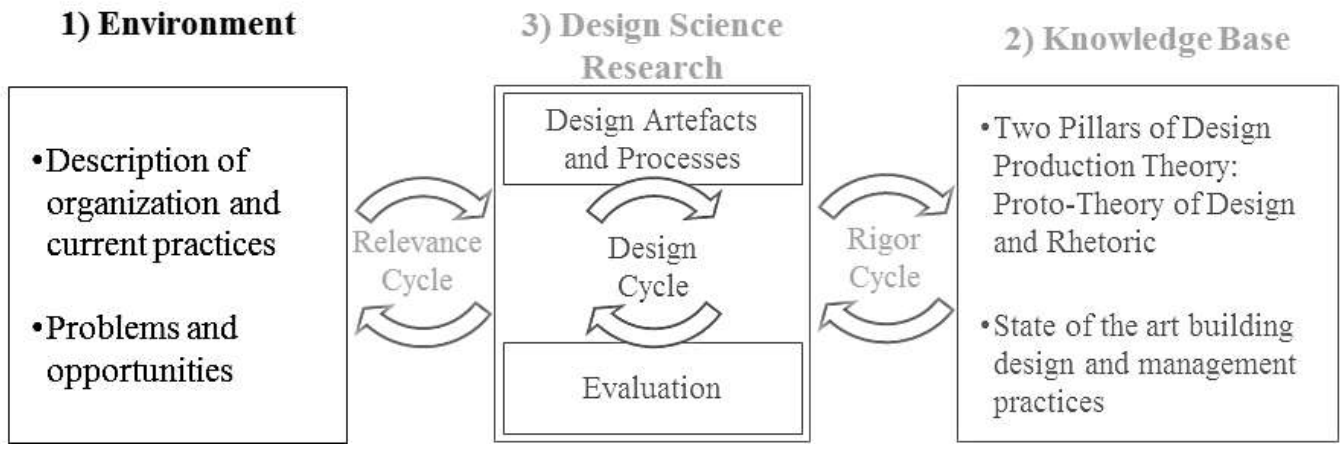

Figure 1. Design science research methodology for developing future design process and management model (adapted from Hevner (2007)).

\section{PROBLEMS AND OPPORTUNITIES FOR IMPROVEMENT}

The Estonian design office founded in 2005 provides multiple design services, including all services of building design and design project management except for the electrical engineering. In 2015, half of the projects were public Estonian projects, and another half were private design projects either in Estonia or in Scandinavian countries, mostly Norway. Company has been using Building Information Modelling (BIM) for the last eight years, and today all projects, no matter the size, are completed in BIM. They have around 40 people working in different departments of the organization. The primary way of standardizing and controlling the quality of the work is the usage of quality system based on ISO9000 quality management standard. 
Ergo Pikas , Lauri Koskela , Olli Seppänen

\subsubsection{Survey and Interview Results}

A survey, compiled in Google Forms, was sent to 34 designers, including architects (10), engineers (12 structural and 8 building services engineers) and project managers (4). Altogether 24 people responded, making the response rate $70.5 \%$. Within the survey, respondents were asked to assess the design management and organization issues statements on five-level Likert scale from strongly disagree to strongly agree. Results were also analyzed according to the disciplines ( 6 architects, 7 building services engineers, 7 structural engineers, 4 project managers) and years of work experience (three $<2$ years, ten 3-5 years, four 6-9 years, four 10-14 years, four $>15$ years).

As for the general problems, the main ones were considered to be poor coordination, intrinsic uncertainty with information flows and clients' lack of timely response. However, the answers varied with respect to respondents' years of experience and discipline. The more experienced designers/engineers did not emphasize the importance of technology, in contrast to the less experienced ones. They also seemed to be more confident regarding knowing where, when and why projects go wrong. For experienced designers, engineers and projects managers, the biggest problems were related to the late changes and lack of information flows and communication.

For project managers, IT solutions played a crucial role and the main issue for project managers was the limited resources for doing the project. For building services engineers, the main problems were related to changes and poor coordination as they are typically at the end of the design production line. The results were confirmed during the group discussion, and designers added that limited time to analyze, plan and also do work is actually one of the major issues.

\subsubsection{ERP Database Analysis}

The case study organization has been using an ERP system for the last seven years. Thus, it was a useful resource for doing a retrospective analysis of completed projects. For conducting a database analysis, the following questions were posed: What type of projects and how successfully has the design office completed? How well are they capable of planning and executing their projects? Where in design process is the time spent? How much resources are spent on fixes, changes and meetings before and after the project contract deadline?

For querying the database, the following criteria were selected: The design office had at the minimum two disciplines working on the project; at least two stages out of typical four (schematic design (SD); preliminary design (PD); design development (DD); and Construction Documents (CD)) were done; projects were executed between January 2014 and September 2016. Altogether, data about 28 projects were analyzed, including 10 housing buildings (35\%), 5 industrial and warehousing buildings (18\%), 4 office and 4 public buildings (14\%), 2 commercial and 2 infrastructure (7\%) and 1 industrial and office project (5\%). Altogether 13,421 data points (activities) with the total time of 51,357 hours were exported to Excel for statistical analysis.

The first thing analyzed was the difference between the planned hours of project work and actual hours of project work. According to the data the design company planned 50795 hours of design work and spent 50,051 hours. This is excluding the sub-contracting hours as there is no actual data about these. Thus in total absolute numbers the difference was $1 \%$, meaning that little less time was spent on work than planned. However, the problem is not in total hours, but in the difference between planned and actual hours within a project, which according to the following building categories were $17 \%$ in Office building, $23 \%$ in Housing, 38\% in Infrastructure, Commercial -6\%, Industrial and Warehousing - 
$10 \%,-9 \%$ in Industrial and Office, and $-136 \%$ in Public Buildings. The variance between estimate and actual was $33 \%$ and standard deviation 58\%. Thus, although overall the projects could be considered successful, on the level of individual projects there is a great variance between the planned and the actual. This means that the company has a lot of variability in projects, and the success of any individual project is uncertain.

The total average of design time consumption in all 28 projects per typical project stages within three different disciplines was calculated. Much time is spent in the DD and CD stages. Little time is spent in SD (2.9\% all together) and PD (9.2\% all together), where the most important decisions are typically made. Moreover, in these early stages, structural and building services disciplines were involved only minimally. However, not all projects had all four stages. For comparison, 12 projects that had at least SD, PD and DD stages were filtered out and in that case the total time spent in each of these stages was $6 \%, 17 \%$ and $77 \%$ respectively. Thus, much time is spent on producing drawings, but not for example working through alternatives for delivering the best value to the customer.

Figure 2 illustrates the total time expenditure with respect to project duration. The same 12 projects with three stages out of 28 were analyzed. For calculating the distribution, all project durations were normalized into 5\% duration increments (thus there were 20 increments) and the curve was produced by using the fourth order polynomial. Projects were divided into two categories, profitable (blue lines) and non-profitable (gray lines). The average contract deadline was determined by adding up all project's end dates in specific increment and divided by the number total number of increments. For example, if one project ended in fourth, the second in ninth and third one in sixth, then the average is 6.33 (calculated as following $(4+9+6) / 3$ ). The figure illustrates that projects where the resource peak fell around the middle of contract duration tend to be more likely profitable. The non-profitable ones had a much flatter resource curve throughout the entire project lifetime. Additionally, all projects within this case study organization had very long tails, including time spent on changes, design fixes and meetings. These tails are the reason for non-profitable projects as most of this time and resources spent are often not reimbursed by the customers due to the type of contracts. Therefore, the conclusion from the figure is that more focus should be put on doing the right things earlier in the project to prevent the loss-causing tails. For metaphorical purpose, if one would compare the two curves to the famous McLeamy curve (McLeamy, P. 2004), clearly the profitable one is closer to that ideal.

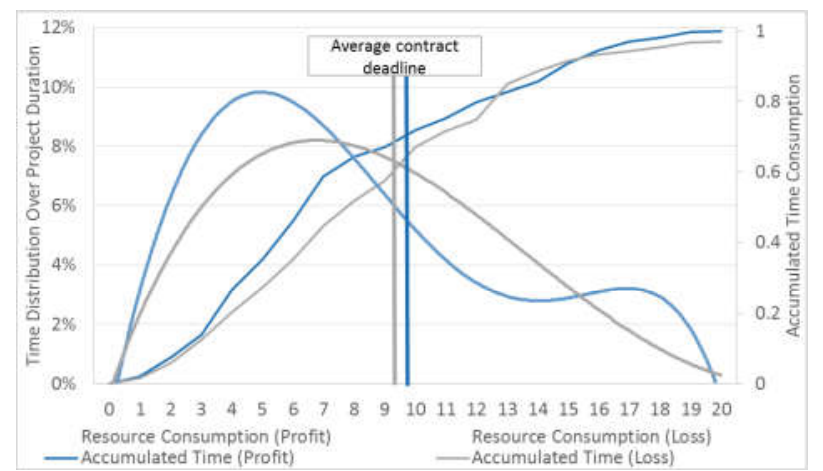

Figure 2. Time consumption over the lifetime of a design project on left and accumulated time consumption on the right axis.

Figure 3 represents the time distribution over 14 different types of activities in all 28 projects for involved disciplines. As the data show, little time is spent on activities such as 
controlling and supervising work inside the discipline, which could be the reason for little control over projects, design problems and errors leading to many fixes. Also, based on the observations and interviews, it is not unusual that projects fall behind the schedule by months without anyone even noticing it. Under control, we do not mean just an inspection of completed work, but a process of making sure that right things get done right at the first time. That is, everybody understand the scope and flow of work, hand-offs, quality criteria and have all necessary inflows to commence and complete the work successfully. Thus, the lack of design production control can be considered one potential cause for project failure.

Based on the classification system of activities used within the company and assuming that design work is value adding and the rest is either non-value adding or other, designers or projects managers spend on average $52 \%$ of all time on design activities, $39 \%$ on nonvalue adding and $9 \%$ on everything else. However, this assessment is a black box as we do not exactly know on what this $52 \%$ was spent by designers and projects managers. For that reason, one project design development stage was observed over eight weeks.

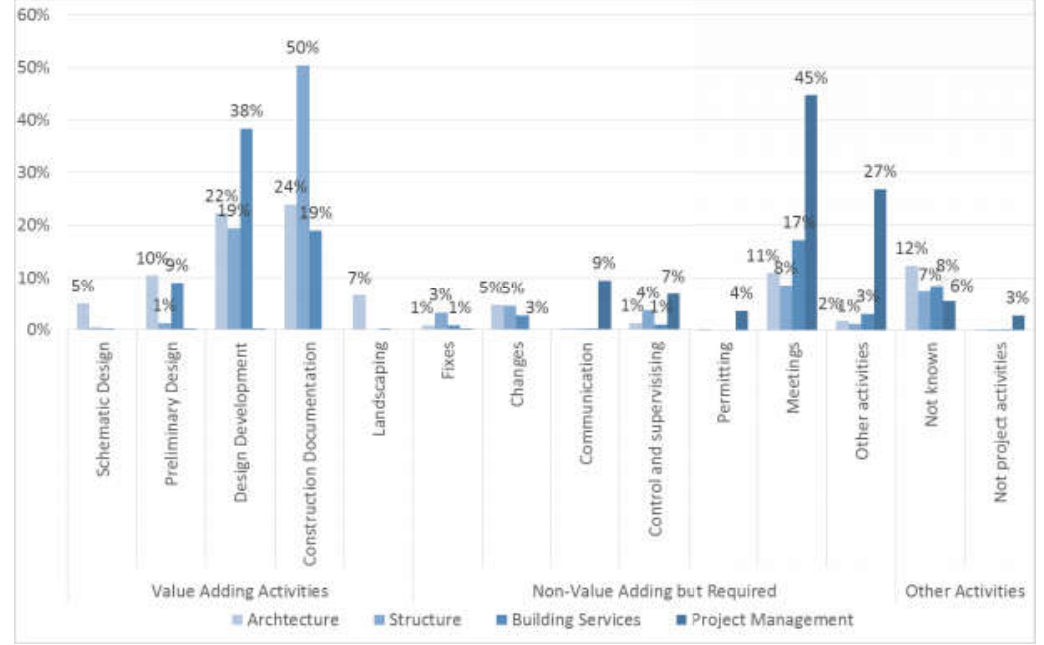

Figure 3. Average activity time distribution per discipline over 28 projects.

\subsubsection{Observation of a Project's Design Development Stage}

The aim of the observations, conducted over eight weeks, and two days in a week between 5.7.2016-1.9.2016, was to get contextual understanding of design and design management problems. Few interventions were introduced to meaningfully collect data, including the co-location of 9 out of 10 (3 architects, 4 structural engineers and 3 building services engineers) design team members from different disciplines and using twice a week standup meetings with sticky note Kanban boards. Observations were conducted on days when the team had stand-up meetings (every Tuesday and Thursday) from morning to evening sitting together with design team members and protocolling all the events of working and communicating with each other.

During eight weeks, the planned work, progress and problems discussed at the standup meetings were used as an input for recording tasks and for observations. Altogether 154 events were recorded during eight weeks and divided into three categories (activities $57 \%$, exchange of information $20 \%$ and problem-solving 23\%). The exchange of information and problem-solving per discipline, such as 3\% exchange of information and $9 \%$ of problem-solving in architecture, show intra-disciplinary communication events. Out of 154 events, 20 were interdisciplinary events: 1 (ca 1\%) activity of a total of $89 ; 9$ (ca 29\%) 
exchanges of information of a total of 31; and 10 (29\%) problem-solving events of a total of 35 .

Only 1 event out of all 89 events was recorded as collaborative work. This occurred when the architect and the building services engineer discussed what should be the elevation of ceilings from floor level in order to provide adequate space for the building services behind it, before the actual design of the ceiling. The data show that even when co-located, the designers worked together only for the reason of exchanging information and problem-solving. Despite for co-location, design process was still fragmented and driven by partial designs. Designs were prepared primarily from the perspective of individual designers first and coordinated only retrospectively. This lack of collaborative working on activities, could be seen as a source for late fixes and changes discussed within section 3.1.2.

Altogether 89 activities were recorded, out of which 58\% were design and engineering activities (calculations, drawings, specifications and model coordination), 28\% changes, $6 \%$ waiting (that means designers had to stop working on an activity and do something else due to a missing input), 5\% control activities and 3\% other activities. Of all the $89(57 \%)$ activities, out of 154 events recorded, only $58 \%$ could be considered directly value-adding and the rest non-value adding. Thus, based on anecdotal evidence, one could argue that the proportion of work directly adding value in design was only around $33 \%$. This is the time when design decisions are converted into design specifications, drawings and calculations, assuming that for example exchanging information or working on the problems, though necessary, are not directly value adding.

Next, problems were analyzed to understand their source. Altogether 35 problems were recorded during observations, of which $9 \%$ were architectural, $20 \%$ structural, $43 \%$ building services related and 29\% interdisciplinary. The problems within disciplines were caused by lack of information, changing requirements that rendered already developed solutions useless, conflicting needs and legislative requirements, faulty input information, and coordination issues between disciplines. For example, a client did not want to have a separate toilet for people working within the kitchen, which however according to legislation is required. Another example is changing equipment technology that required all new building services solutions. Interestingly, $26 \%$ percent of the problems were related to the usage of ICT systems. Either something could not be modelled or there was a lack of knowledge on how to use the application for a specific situation.

As the last step, communication or information exchange practices were also observed. Altogether 33 communication events were recorded. These could be divided into five categories: $29 \%$ was intra-disciplinary communication and consulting on solutions; $26 \%$ interdisciplinary coordination; $23 \%$ software training; $16 \%$ intra-disciplinary coordination; and $6 \%$ related to drafting conventions. When design team members communicated with each other, almost always some tool or object was used as a reference for communication. Out of 31 communication events, in $55 \%$ of the cases some sort of computer drafting or modelling application was used; in $21 \%$ of the cases designers used sketches either on drawings (mostly related to discussing changes) or on blank paper (mostly for drafting structural connections); in $18 \%$ of the cases, designers did not use any specific tool but communication was verbal; and in $6 \%$ of the cases something else was used (e.g. excel or project documentation server).

Before and during the project, interviews with team members were conducted for evaluating the effect of interventions. The main benefit of co-location, according to team members, was the reduction of time spent on problem-solving. The observations agree 
with their assessment as several problems were solved on the spot, when they had emerged.

Based on the observations, other conclusions were drawn. The level of task break-down or resolution differentiated between different disciplines. Co-location improved the reaction speed and efficiency of problem-solving. On the other hand, the focus was on problem-solving instead of avoiding these in the first place as there was little discussion on how something should be designed. It was observed that the architect who sat separately in her department did not participate that much in different conversations, indicating that physical distance can play an important role. Experience but as well as social skills played a crucial role in initiating and facilitating discussions.

\subsubsection{Summary and Generalization of As-Is Situation}

This study approached the design management from a design office's perspective, not commonly adopted in the lean construction community. However, it is important that design offices have capacity to manage their internal processes as any project delivery is as successful as its weakest link. Designers have an important role to play within building projects, they are the mediating actors between customer and the contractor.

Based on the surveys, interviews, database analysis and observations, several conclusions were drawn on causes that make projects and project results highly unpredictable. Design management has focused on planning projects, tasks and resources, but not on managing the design process and value.

Design management control is primarily based on the thermostatic model of control (Koskela and Howell, 2002), monitoring deviations between planned and actual resource consumption and task completion during design meetings (e.g. $45 \%$ of project managers' time is spent in meetings). The process of making work ready is carried out in a short term perspective and motivated by urgency within weekly meetings. Much time is spent on producing drawings, but not working through alternatives for delivering best value to the customer. Based on database analysis and observations, only little time is spent on controlling and supervising work activity at the unit level (1\% in architecture and building services engineering, $4 \%$ in structural engineering and $7 \%$ in project management). There is no reason to assume that the whole will work if one or several elementary units do not.

The study results support the findings of other studies discussed in the introduction. However, we hypothesized that it is the poor understanding of design and design management that have led to the bad consequences. Indeed, the evidence in this study show that design management is narrow-minded and founded on the conceptualization of design production as a transformation of inputs to outputs, missing flow and value views (Koskela 2000). Traditional project management was the only visible method/framework in use, and the outcomes corresponded to what critical accounts of it have argued to occur due to poor conceptualization.

\section{CONCLUSIONS}

Any act of design requires understanding of the current environment and situation to close the gap, or, in another words, how things are and how they ought to be. Within this article, the aim was to solve the problem of relevance, and for that relevant practical but also theoretical problems were articulated. In summary, the main problems observed within the case study organization include: poor conceptualization of design task; focus is on production of drawings and models; late changes and patching; unaligned work scope; unpredictable projects and plans; and poor design quality. Traditional project management 
was the only visible method/framework in use, and the outcomes corresponded to what critical accounts of it have argued to occur due to poor conceptualization. This becomes the material for defining the requirements and carrying out the subsequent DSR stages for developing a proper theoretical knowledge base in the next paper, and for developing the theoretical as well as practical design management model within the third paper.

\section{REFERENCES}

Arnell, V., Y. Hammarlund, M. Liedholm and P. Sverlinger (1996). "Kvalitetsförbättringar i bygg-och anläggningsprojekt." Chalmers Tekniska Högskola, Institutionen för byggnadseconomi och byggnadsorganisation, Report 47: 12 .

Ballard, G. and L. Koskela (1998). On the agenda of design management research. Proceedings of the Eighth Annual Conference of the International Group for Lean Construction, IGLC-6, Guarujá, Brazil.

Fosse, R. and G. Ballard (2016). Lean Design Management in Practice With the Last Planner System. 24th Annual Conference of the International Group for Lean Construction, Boston, USA.

Freire, J. and L. F. Alarcón (2002). "Achieving lean design process: improvement methodology." Journal of Construction Engineering and management 128(3): 248-256.

Hevner, A. R. (2007). "A three cycle view of design science research. "Scandinavian journal of information systems 19 (2): 4.

Howell, G. A., G. Ballard and I. Tommelein (2010). "Construction engineeringReinvigorating the discipline." Journal of construction engineering and management 137(10): 740-744.

Koskela, L. (2000). An exploration towards a production theory and its application to construction, VTT Technical Research Centre of Finland.

Koskela, L. (2008). Which kind of science is construction management? Proceedings of the 16th IGLC Conference, Manchester, July, Citeseer.

Koskela, L., P. Huovila and J. Leinonen (2002). "Design management in building construction: from theory to practice." Journal of Construction Research 3(01): 1-16.

Kuechler, B. and V. Vaishnavi (2011). Extending prior research with design science research: two patterns for DSRIS project generation. Service-Oriented Perspectives in Design Science Research, Springer: 166-175.

McLeamy, P. (2004). Integrated Project Delivery: McLeamy Curve.

Pikas, E., L. Koskela, B. Dave and R. Liias (2015). Case Study on Design Management: Inefficiencies and Possible Remedies 23rd Annual Conference of the International Group for Lean Construction. O. In: Seppänen, González, V.A. \& Arroyo, P. Perth, Australia: 547-557.

Rocha, C., C. T. Formoso, P. Tzortzopoulos Fazenda, L Koskela and B. Tezel (2012). "Design science research in lean construction: process and outcomes." 